\title{
Thermally Identified Subgroups of Marginal Zone Neurons Project to Distinct Regions of the Ventral Posterior Lateral Nucleus in Rats
}

\author{
Xijing Zhang, Steve Davidson, and Glenn J. Giesler Jr \\ Department of Neuroscience, University of Minnesota, Minneapolis, Minnesota 55455
}

\begin{abstract}
Spinal marginal zone (MZ) neurons play a crucial role in the transmission of nociceptive and thermoreceptive information to the brain. The precise areas to which physiologically characterized MZ neurons project in the ventral posterior lateral (VPL) nucleus of the thalamus have not been clearly established. Here, we examine this projection in rats using the method of antidromic activation to map the axon terminals of neurons recorded from the MZ. Thirty-three neurons were antidromically activated using pulses of $\leq 30 \mu \mathrm{A}$ in the contralateral VPL. In every case, the most rostral point from which the MZ neuron could be antidromically activated was surrounded by stimulating tracks in which large-amplitude current pulses failed to activate the examined neuron, indicating the termination of the spinothalamic tract (STT) axon. Each of 30 examined neurons responded to noxious but not innocuous mechanical stimuli applied to their cutaneous receptive fields, which ranged in size from two digits to the entire limb. Of 17 thermally tested neurons, 16 responded to innocuous or noxious thermal stimuli. Among STT neurons that responded to thermal stimuli, 50\% responded to innocuous cooling as well as noxious heat and cold, 31\% responded to noxious heat and cold, and 19\% responded only to noxious heat. Axons from cells responsive to innocuous cooling terminated in the core region of VPL, significantly dorsal and medial relative to other thermally responsive subgroups. In rats, thermally responsive subgroups of MZ neurons project directly to distinct regions of VPL.
\end{abstract}

Key words: spinothalamic; nociception; marginal zone; thalamus; pain; temperature

\section{Introduction}

Marginal zone (MZ) neurons in the spinal cord receive direct and modality-selective input from $\mathrm{A} \delta$ and $\mathrm{C}$ primary afferent thermoreceptors and nociceptors (Christensen and Perl, 1970; Light et al., 1979) and play an important role in transmitting sensory information regarding the discrimination of thermal and noxious stimuli to thalamus (Willis et al., 2002). Neurophysiological studies in cats and monkeys have shown that thermoreceptive and nociceptive spinothalamic tract (STT) neurons in the MZ project to the ventral posterior lateral nucleus (VPL) (Willis et al., 1974; Price et al., 1978; Ferrington et al., 1987; Craig and Dostrovsky, 2001; Simone et al., 2004). However, this projection has remained unexplored in the rat. Because useful neuropathological models and neuropharmacological and behavioral studies related to pain and analgesia are overwhelmingly performed in the rat, we sought to assess for the first time the response characteristics of MZ neurons projecting to VPL in this species.

Based on cat and monkey experiments, Craig and colleagues (Dostrovsky and Craig, 1996; Craig et al., 2001) have proposed that spinothalamic MZ neurons fall within three main categories

Received Feb. 16, 2006; revised April 4, 2006; accepted April 12, 2006

This work was supported by National Institutes of Health Grants NS25932 and NS047399. We thank Hai Truong for his valuable technical assistance and Dr. Donald Simone for critically reading this manuscript.

Correspondence should be addressed to Glenn Giesler, Department of Neuroscience, 6-145 Jackson Hall, University of Minnesota, Minneapolis, MN 55455. E-mail: giesler@umn.edu.

DOI:10.1523/JNEUROSCI.0701-06.2006

Copyright $\odot 2006$ Society for Neuroscience $\quad$ 0270-6474/06/265215-09\$15.00/0 defined by their response to thermal and mechanical stimuli. Nociceptive-specific cells respond to noxious mechanical and heat stimuli, polymodal nociceptive cells respond to noxious mechanical, heat, and cold stimuli, and "COOL" cells respond to innocuous cooling and noxious cold. These cell types are believed to have differing morphology, conduction velocities, and projection targets within the thalamus (Han et al., 1998; Craig and Dostrovsky, 2001; Craig et al., 2001). Thermally driven projection neurons have been documented recently within the rat MZ (Bester et al., 2000; Todd et al., 2005); however, no physiological study has characterized the response of MZ STT neurons to a range of thermal stimuli or determined their projection sites within the thalamus.

Marginal zone neurons have been antidromically activated from the thalamus in previous neurophysiological studies using stationary, large-amplitude stimulus pulses, making the nuclei to which the axons project difficult to determine and leaving open the possibility of stimulating axons of passage (Willis et al., 1974; Price et al., 1978; Ferrington et al., 1987; Dostrovsky and Craig, 1996). Furthermore, the potential that current spread out of the thalamus to activate axons that terminated in other areas of the diencephalon cannot be ruled out. Whether a meaningful population of MZ neurons project to VPL at all has been questioned recently for primates and cats (Craig et al., 1994; Blomqvist et al., 2000; Craig, 2004), sparking debate (Willis et al., 2001, 2002; Graziano and Jones, 2004). In the rat, a comprehensive anatomical study documenting terminations of spinal MZ neurons in the 
diencephalon showed that VPL was the single largest projection target (Gauriau and Bernard, 2004).

The goals of the present study were to (1) map the projection areas of MZ neurons to VPL in the rat, (2) characterize the responses of these cells to a series of innocuous and noxious mechanical and thermal stimuli, and (3) determine whether the categories of MZ STT neurons described in cats and monkeys also exist in rats.

\section{Materials and Methods}

In accordance with the Institutional Animal Care and Use Committee, male Sprague Dawley rats weighing 300-450 g were deeply anesthetized with urethane $(1.3 \mathrm{~g} / \mathrm{kg}$, i.p.), artificially ventilated, and paralyzed with Flaxedil $(20 \mathrm{mg} / \mathrm{h})$ through a cannula inserted into the external jugular vein. End-tidal $\mathrm{CO}_{2}$ and core temperature were monitored and maintained at physiological levels. The cervical or lumbar enlargement of the spinal cord was exposed by laminectomy. The dura was retracted, and a pool of warm mineral oil was formed over the exposed area of the spinal cord. A craniotomy exposed the brain over the diencephalon to allow the insertion of stainless steel monopolar stimulating electrodes.

Cathodal current pulses ( $500 \mu \mathrm{A}, 200 \mu \mathrm{s}, 10 \mathrm{~Hz})$ delivered through the stimulating electrode placed in the contralateral posterior thalamus served as the search stimulus. This protocol has been shown to stimulate axons with a wide range of conduction velocities, including the unmyelinated range (Zhang and Giesler, 2005). Single units in the cervical or lumbar enlargement of the spinal cord were recorded using stainless steel electrodes $(5-10 \mathrm{M} \Omega)$. The criteria used for antidromic activation consisted of the following: response at a relatively constant latency $(<0.2 \mathrm{~ms}$ variability), ability to follow high-frequency stimuli ( $\geq 333 \mathrm{~Hz}$ ), and the collision of putative antidromic with orthodromic action potentials (Lipski, 1981). Once an antidromically activated unit was isolated, antidromic mapping was done to locate the axon termination within the thalamus.

Antidromic mapping in the contralateral diencephalon was done as described previously by Dado et al. (1994a) and Zhang et al. (1995). Briefly, after unit isolation, the stimulating electrode was moved rostrally, and a row of electrode penetrations was made every 300-500 $\mu \mathrm{m}$ across the mediolateral extent of the contralateral hemisphere. Within each track, the electrode was lowered in $200 \mu \mathrm{m}$ intervals from the dorsal to the ventral surface of the brain, and antidromic thresholds were determined at each step. If the neuron could be antidromically activated from a level rostral to the thalamus or from the hypothalamus, the unit was discarded and a search for another spinal unit followed. If the neuron could not be activated antidromically from this rostral level, the stimulating electrode was moved $1 \mathrm{~mm}$ caudally and another row of electrode penetrations was made across the mediolateral extent of the hemisphere. This was repeated until the most rostral point within the thalamus was found at which the MZ neuron could be antidromically activated by a current pulse $\leq 30 \mu \mathrm{A}$, defined as a low-threshold point. Current pulses $\leq 30 \mu \mathrm{A}$ have been shown to activate spinohypothalamic tract axons at a distance of $\leq 400 \mu \mathrm{m}$ from the stimulating electrode (Burstein et al., 1991; Dado et al., 1994a). To resolve the putative terminal area of the axon, the most rostral low-threshold point was surrounded rostrally, medially, and laterally with stimulating electrode penetrations in which the axon could not be activated antidromically with up to $500 \mu \mathrm{A}$. Failure to activate the axon antidromically with a $500 \mu \mathrm{A}$ pulse was taken as evidence that the axon did not pass through the stimulated areas (Zhang et al., 1995). Each unit in this study was antidromically activated using $\leq 30 \mu \mathrm{A}$ current pulses, and each low-threshold point was histologically confirmed.

Cutaneous receptive fields and the response characteristics of recorded cells were determined using innocuous and noxious mechanical stimuli. Neurons were classified as "high threshold" (HT) if brushing their receptive field failed to increase the firing rate by 1.5 spikes/s over baseline; otherwise, they were classified as "wide dynamic range" (WDR). Thermal stimuli were applied to the area of the cutaneous receptive field in which mechanical stimuli produced the highest frequency response. Thermal stimuli were delivered using a peltier-type stimulator with a contact area of $9 \times 9 \mathrm{~mm}$ (Wilcox and Giesler, 1984) for a duration of $30 \mathrm{~s}$ and with an interstimulus interval of $180 \mathrm{~s}$. The stimulated surface of the skin was maintained at $35^{\circ} \mathrm{C}$ during the interstimulus intervals. The mean response frequency to each stimulus was defined as the mean frequency during the stimulus subtracted by the mean frequency during the $30 \mathrm{~s}$ before each stimulus. An increase in the firing rate by $1.5 \mathrm{spikes} / \mathrm{s}$ was defined as the response threshold. To minimize the effect of sensitization caused by noxious stimuli, the series of thermal stimuli were delivered in the following order: innocuous warm $\left(35\right.$ and $\left.40^{\circ} \mathrm{C}\right)$, innocuous cool $(30$, 25 , and $20^{\circ} \mathrm{C}$ ), noxious heat $\left(45,50\right.$, and $55^{\circ} \mathrm{C}$ ), and finally noxious cold $\left(15,10,5\right.$, and $\left.1{ }^{\circ} \mathrm{C}\right)$. Temperatures were increased by $10^{\circ} \mathrm{C} / \mathrm{s}$ and decreased by $2^{\circ} \mathrm{C} / \mathrm{s}$.

At the end of each experiment, an electrolytic lesion was made at the tip of the stimulating electrode located at the low-threshold point in the brain (25 $\mu \mathrm{A}$ for $40 \mathrm{~s})$ and at the tip of the recording electrode in the spinal cord $(25 \mu \mathrm{A}$ for $15 \mathrm{~s})$. Rats were perfused with $0.9 \%$ saline, followed by $10 \%$ Formalin containing $1 \%$ potassium ferrocyanide (Prussian blue reaction). The areas of the brain and spinal cord containing lesions were cut transversely using a freezing microtome into 75 and $50 \mu \mathrm{m}$ sections, respectively. Sections were counterstained with neutral red and examined under a microscope. The locations of lesions were reconstructed with the aid of an attached camera lucida. For statistical analysis of the locations of the lesions marking low-threshold points in the brain, the distance of each lesion was measured from the border between ventral posterior medial nucleus (VPM) and VPL using the camera lucida reconstructions, and then the Student's $t$ test was applied. The atlas of Paxinos and Watson (1986) was used to help identify the locations of lesions within the brain.

\section{Results}

\section{Marginal zone neurons project directly to VPL in rats}

Thirty-three MZ neurons were antidromically activated by current pulses $\leq 30 \mu \mathrm{A}$ in the contralateral VPL. Each of these lowthreshold points was surrounded by stimulating tracks in which $500 \mu \mathrm{A}$ could not activate the cell. An example is illustrated in Figure 1. The stimulating electrode was initially placed at the level of the posterior thalamus. After a single, antidromically activated unit was isolated in the spinal cord, the stimulating electrode was moved rostrally, and rows of stimulating tracks were made in the diencephalon while the minimum current amplitudes that could antidromically activate the neuron were recorded (Fig. $1 A$ ). The low-threshold point for antidromic activation was $15 \mu \mathrm{A}$, and the latency for the action potential to reach the soma from this point was $9.7 \mathrm{~ms}$. The low-threshold point was surrounded medially, laterally, and two levels rostrally by ineffective stimulation tracks in which $500 \mu \mathrm{A}$ pulses could not activate the neuron antidromically, indicating that the axon terminated in this area. A lesion marking the low-threshold point was located in VPL (Fig. 1B). The neuron was recorded from the MZ of C7 (Fig. 1C), had a small cutaneous receptive field on the ipsilateral forelimb (Fig. $1 D$ ), and responded to intense mechanical stimulation (Fig. $1 E$ ). Antidromic action potentials (Fig. $1 F$ ) occurred at a constant latency $(f 1)$, followed high-frequency stimulation ( $f 2)$, and collided with orthodromic action potentials ( f3), indicating a direct projection from the MZ to VPL. This neuron responded to thermal stimulation in the range of noxious heat (Fig. 1G,H). Photomicrographs of representative lesions that marked the lowthreshold point in the VPL of the thalamus and at the recording point in the $\mathrm{MZ}$ are shown in Figure 2, $A$ and $B$.

A representative example of a neuron that responded well to innocuous cool temperatures applied to its receptive field is illustrated in Figure 3. The low-threshold point was surrounded in VPL near the border of VPM, and the cell was recorded in the MZ (Fig. 3A-C). It possessed a large receptive field on the ipsilateral forelimb and was activated only by intense mechanical stimuli 


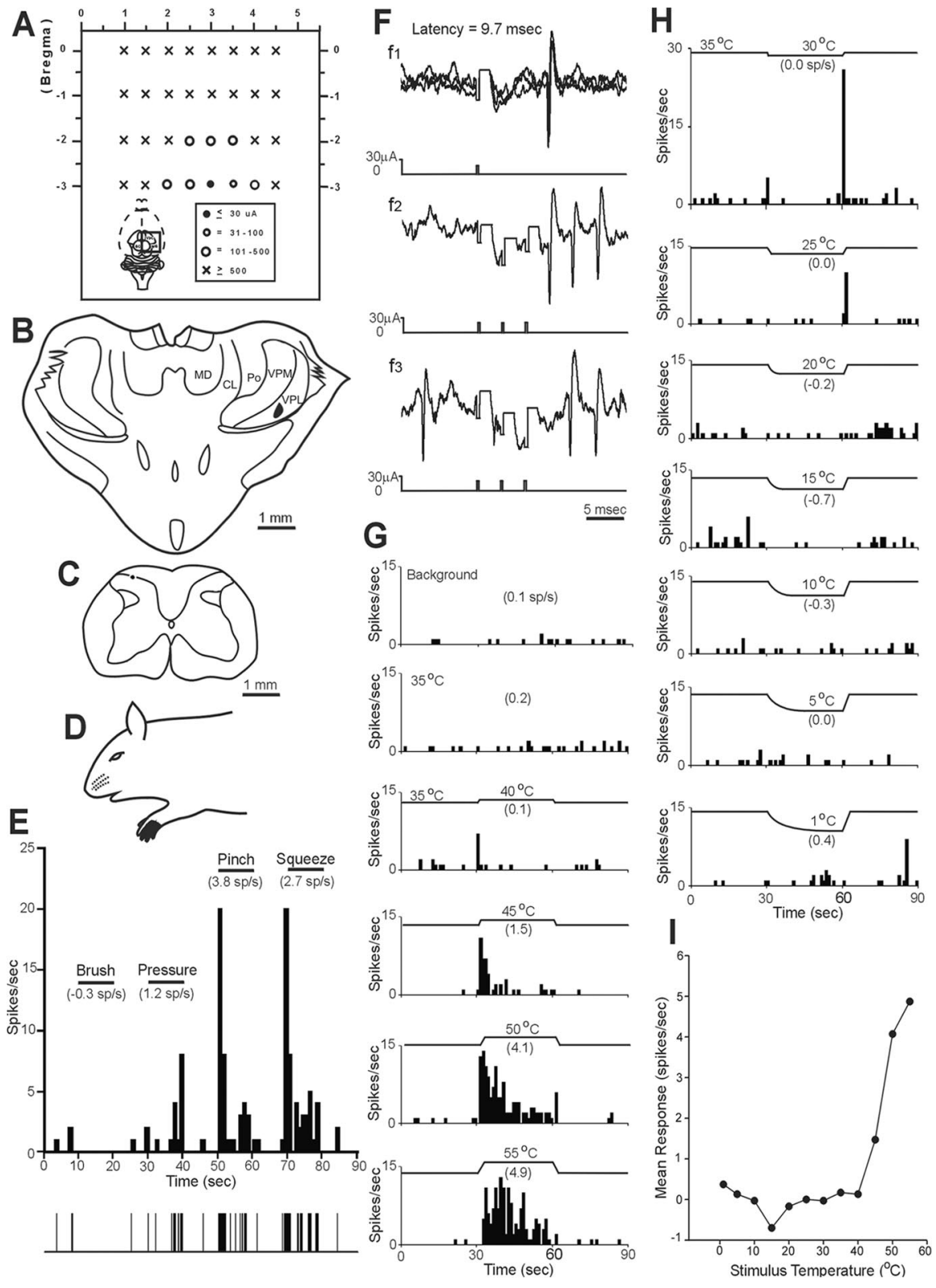

Figure 1. Example of a nociceptive-specific neuron in C7 spinal cord with an axon that projects to the contralateral VPL of the thalamus. $\boldsymbol{A}$, A dorsal representation of stimulating electrode penetrations into the diencephalon at multiple rostrocaudal levels. This region is indicated by the black square in the whole-brain inset. The minimum current required for antidromic activation in each penetration is represented by a symbol (right inset). Note that the low-threshold point was surrounded medially, laterally, and rostrally by ineffective stimulation tracks, indicating the axon terminal area. CL, Centrolateral nucleus; MD, mediodorsal thalamic nucleus. $\boldsymbol{B}$, Coronal section showing a lesion marking the low-threshold point in contralateral VPL. $\boldsymbol{C}$, Lesion marking the recording site in the marginal zone. $\boldsymbol{D}$, Receptive field on ipsilateral forepaw. $\boldsymbol{E}$, Response of this neuron to increasingly intense cutaneous mechanical stimuli. Mean firing frequency (mean frequency during stimulation - mean background frequency) is indicated in parentheses. $\boldsymbol{F}$, The antidromic response had a stable latency (3 overlapping traces), followed a high-frequency (333 $\mathrm{Hz}$ ) train and collided with an orthodromic action potential within the critical window. Note that the stimulus artifact has been reduced for clarity here and also in Figure $4 F, G, H$, The neuron responded to noxious heat stimuli applied to its cutaneous receptive field. The peculiar brief discharge during the cooling stimulus offset was unique to this particular cell. $I$, Line graph showing the response to a range of thermal stimuli.

(Fig. $3 D, E$ ). Figure $3 F$ shows a graded, increasing response to decreasing temperatures applied to the receptive field. At the holding temperature $\left(35^{\circ} \mathrm{C}\right)$, the discharge rate was reduced compared with background activity recorded at room temperature $\left(23^{\circ} \mathrm{C}\right)$. The cell also responded intermittently as the temperature approached $55^{\circ} \mathrm{C}$ (Fig. $3 G, H$ ).

Figure 4 illustrates an antidromically activated $\mathrm{MZ}$ neuron that terminated in VPL (Fig. $4 A-C, F$ ) and responded well to noxious heat and cold (Fig. 4G-I). During the thermal ramp to innocuous warm and cool temperatures, a phasic and weak discharge was observed. This cell was also activated by intense mechanical stimulation of its receptive field (Fig. 4D,E).

\section{Classification by response to cutaneous} thermal stimuli

Seventeen MZ neurons antidromically activated from VPL were tested for responsiveness to a series of thermal stimuli, including innocuous warming and cooling, noxious heat, and cold. Sixteen of 17 responded to at least one kind of thermal stimulus applied to their cutaneous receptive field. Of the 16 thermally responsive MZ neurons, each could be classified as one of three types. Half (eight) responded in a graded manner to innocuous cooling. These cells also responded to noxious cold and high heat stimuli as well as to noxious mechanical stimuli applied to their receptive fields (Fig. 3). This group of neurons appeared to be best suited to code for innocuous cooling of the skin and were classified as the COOL type. The individual and overall mean \pm SE responses of the eight neurons with this pattern of activation by thermal stimuli are shown in Figure 5, $A$ and $D$. Spontaneous activity at room temperature allowed these cells to be easily identified from other cell types (Fig. 6A). A reduction in spontaneous activity always occurred during contact with the $35^{\circ} \mathrm{C}$ thermal probe, indicating that the activity was a response to room temperature (Fig. 3G). Six of eight COOL cells responded to the $30^{\circ} \mathrm{C}$ stimulus; one cell responded at $25^{\circ} \mathrm{C}$ and another at $35^{\circ} \mathrm{C}$. As temperatures decreased from threshold to 15 or $10^{\circ} \mathrm{C}$, the response increased linearly. When temperatures in the noxious range $\left(10-1^{\circ} \mathrm{C}\right)$ were delivered, the neural firing rate reached a plateau. Every COOL cell responded to high noxious heat $(50-$ $\left.55^{\circ} \mathrm{C}\right)$, although the responses were small and of an irregular pattern (Fig. $3 G$ ).

Five neurons responded to noxious heat, cold, and intense mechanical stimuli but did not respond or responded weakly to innocuous cool or warm. This group of cells was classified as the polymodal nociceptive type. An example of this cell type is shown in Figure 4. Two polymodal nociceptive-type cells displayed phasic activity to innocuous cool temperatures above $20^{\circ} \mathrm{C}$. However, these could be distinguished from COOL cells by (1) a lack of spontaneous activity at room temperature (Fig. 6A), (2) no inhibition to the $35^{\circ} \mathrm{C}$ probe, and (3) a graded, increasing discharge to noxious cold and heat (Fig. 4G,H). The individual and overall mean \pm SE responses of five polymodal-nociceptive- 
type neurons to thermal stimuli are shown in Figure 5, $B$ and $E$. Three neurons responded only to noxious heat and mechanical stimuli and were classified as nociceptive-specific-type neurons. An example of this cell type is shown in Figure 1. The individual and overall mean \pm SE responses of nociceptive-specific neurons to thermal stimuli are shown in Figure 5, $C$ and $F$.

Stimulus-response curves of thermally identified subgroups were plotted within their respective temperature coding ranges on a double-logarithmic plot (Fig. 6B). The slope of each regression line equals the exponent of a power function representative of the relationship between thermal stimulation and firing frequency. For cooling and cold stimuli, the slope of the COOL cell response from 30 to $10^{\circ} \mathrm{C}$ was $0.93\left(r^{2}=0.99\right)$ and for the polymodal cells from 20 to $1^{\circ} \mathrm{C}$ was $1.3\left(r^{2}=0.65\right)$. The polymodal cells also coded for heat at 45,50 , and $55^{\circ} \mathrm{C}$ with a regression line of slope $1.5\left(r^{2}=\right.$ 0.99 ), indicating a positively accelerating function. By extending each regression line to the point at which it intercepts the 1.5 spikes/s increase over baseline firing rate, the threshold for response to thermal stimulation was extrapolated. For cooling, the COOL cell threshold was $33.3^{\circ} \mathrm{C}$ and polymodal cell threshold was $22.8^{\circ} \mathrm{C}$. For heating, the threshold for response of polymodal cells was $40.0^{\circ} \mathrm{C}$.

\section{Mechanical stimulation of cutaneous receptive fields}

Thirty of the 33 antidromically activated neurons were physiologically characterized by responses to mechanical stimulation delivered to their receptive fields. Every unit responded to noxious but not innocuous mechanical stimuli and was therefore classified as HT. Examples of three MZ STT neurons that responded to noxious but not innocuous mechanical stimuli are shown in Figures $1 E, 3 E$, and $4 E$.

All 30 examined neurons had cutaneous receptive fields that were restricted to the ipsilateral limb or paw (Fig. 7). Of thermally tested units, all COOL neurons had receptive fields that extended over parts of the entire limb, including digits, paw, and forelimb. Fewer than half of polymodal nociceptive and none of the nociceptive-specific neurons had receptive fields as large. Of the units not thermally tested, approximately half had receptive fields extending over parts of the entire limb.

\section{Conduction velocity}

The mean antidromic latency to record an action potential in the cervical enlargement from the low-threshold points in the contralateral VPL of the thalamus for 30 examined $\mathrm{MZ}$ neurons was $7.7 \pm 0.9 \mathrm{~ms}$ (range of 4.1-14.8 ms). Assuming that the axons crossed in the spinal cord and then ascended in a straight path to the thalamus, the estimated mean conduction ve-
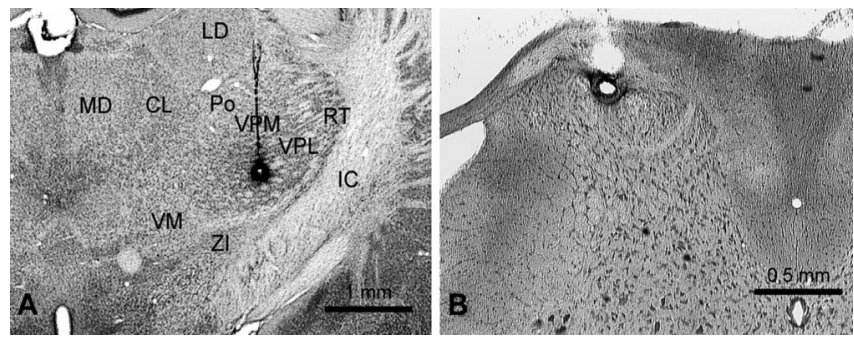

Figure 2. Photomicrographs of representative lesions. $\boldsymbol{A}$, Lesion marking a completely surrounded low-threshold point for antidromic activation in the contralateral VPL of the thalamus. $\mathrm{CL}$, Centrolateral thalamic nucleus; IC, internal capsule; LD, laterodorsal thalamic nucleus; MD, mediodorsal thalamic nucleus; RT, reticular thalamic nucleus; VM, ventromedial thalamic nucleus; $\mathbf{Z l}$, zona incerta. $\boldsymbol{B}$, Lesion marking the recording site in the marginal zone of the cervical enlargement.
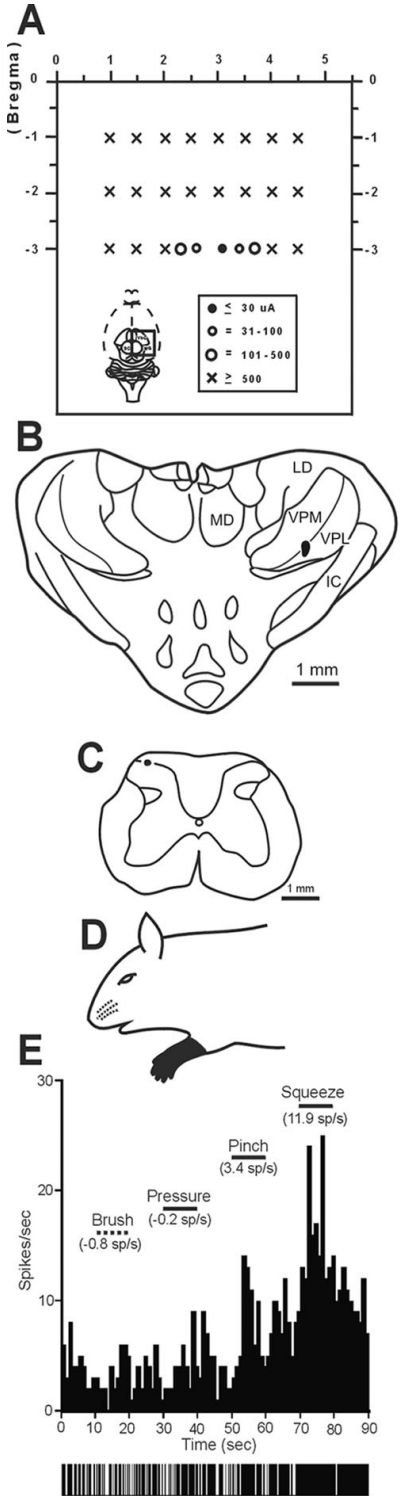

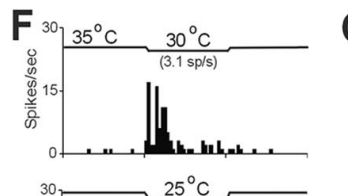

G
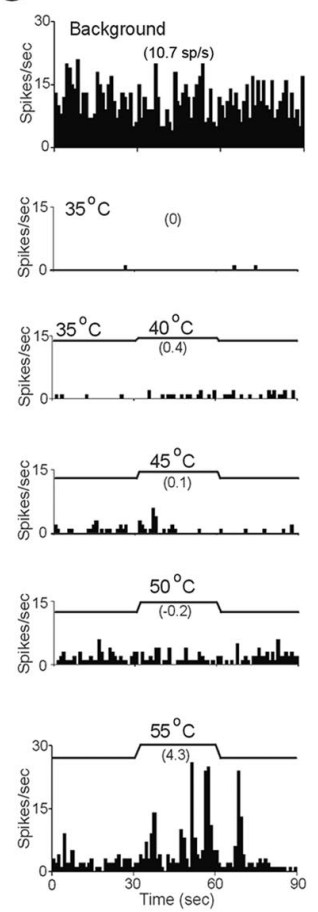

$\mathrm{H}$
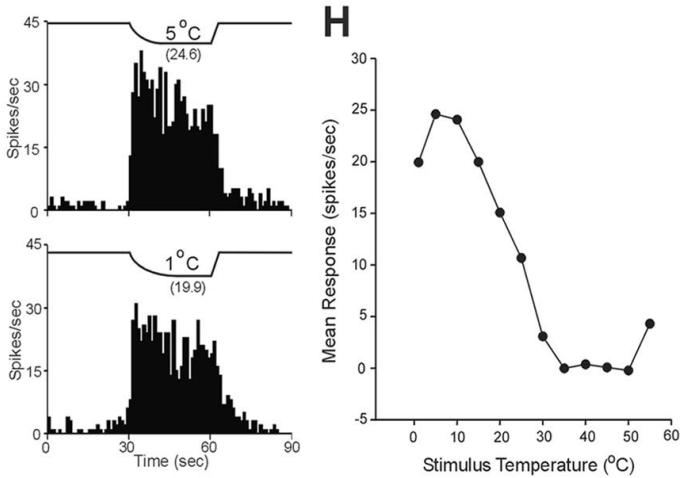

Figure 3. Example of a $\mathrm{COOL}$ neuron in the $\mathrm{C} 7$ segment with an axon that projected to contralateral VPL. $\boldsymbol{A}$, Schematic representation of dorsal view of the brain indicating locations of stimulating tracks. The low-threshold point was surrounded medially, laterally, and rostrally by tracks in which $500 \mu$ A current pulses did not antidromically activate this axon. $B$, Cross section showing the low-threshold point located in contralateral VPL. IC, Internal capsule; LD, laterodorsal thalamic nucleus; MD, mediodorsal thalamic nucleus. $\boldsymbol{C}$, Recording site in the marginal zone of C7. D, Receptive field covered the entire ipsilateral forelimb. $\boldsymbol{E}$, This cell responded to only high-intensity mechanical stimuli applied to its cutaneous receptive field. $\boldsymbol{F}, \boldsymbol{G}$, Innocuous cool, noxious cold, and heat stimulation elicit increased activity from this unit. $\boldsymbol{H}$, Line graph shows the response of this unit to thermal stimuli across a range of temperatures. 

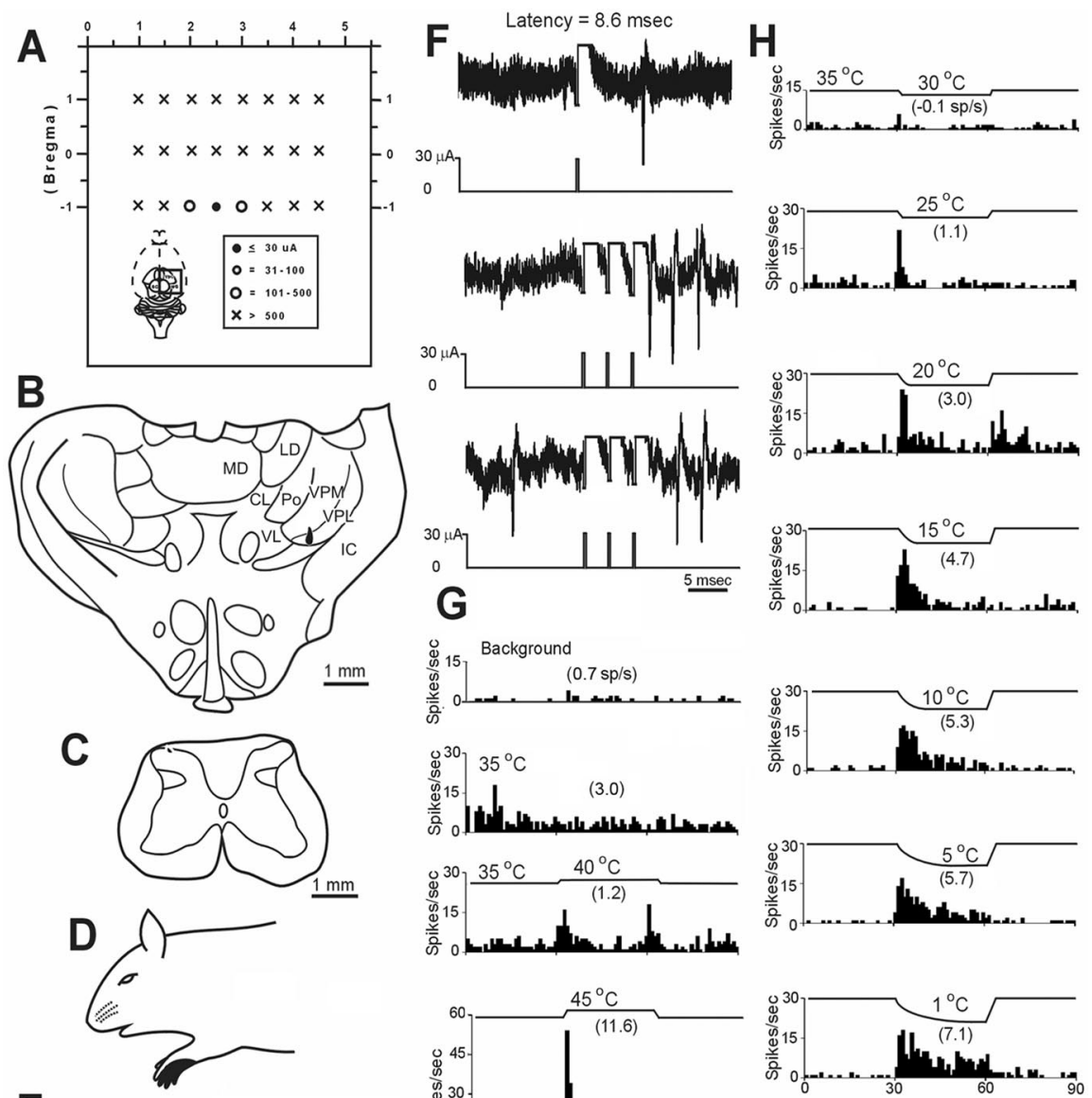

E
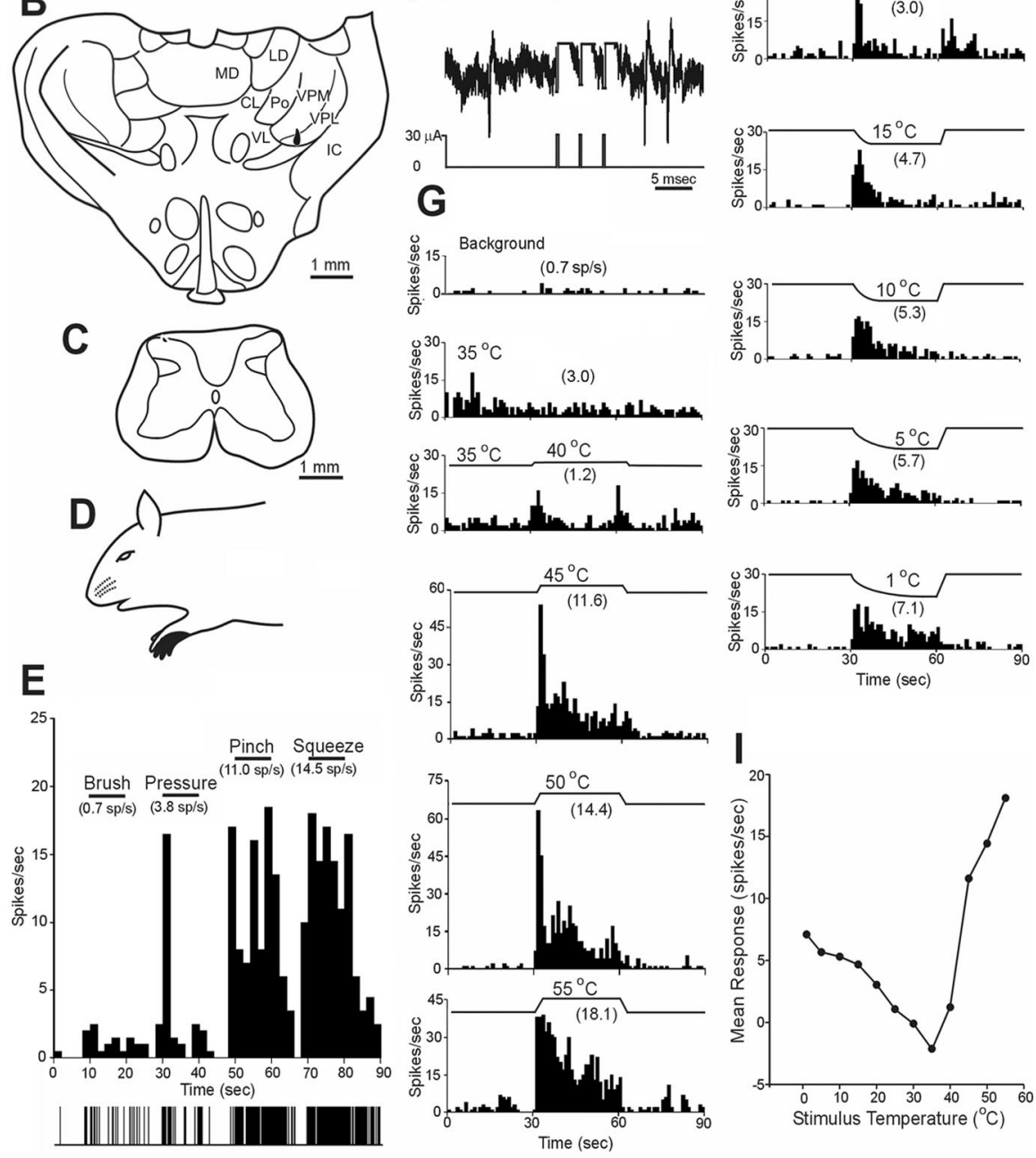

Figure 4. Example of a polymodal nociceptive neuron in the C7 that projected to contralateral VPL. $A$, Schematic representation of the dorsal view of the brain indicating locations of stimulating tracks. The current amplitude required to activate the neuron antidromically is indicated. $\boldsymbol{B}$, The lesion marking the low-threshold point was located in contralateral VPL. CL, Centrolateral thalamic nucleus; IC, internal capsule; LD, laterodorsal thalamic nucleus; MD, mediodorsal thalamic nucleus; VL, ventrolateral thalamic nucleus. This neuron was recorded in $C 7(\boldsymbol{C})$ and had a relatively small cutaneous receptive field on the forepaw $(\boldsymbol{D})$. The neuron responded only to noxious mechanical stimulation and was classified as an HT neuron $(\boldsymbol{E})$. $\boldsymbol{F}$, The antidromic response had a stable latency (3 overlapping traces), followed a high-frequency $(333 \mathrm{~Hz})$ train, and collided with an orthodromic action potential. $\mathbf{G}, \boldsymbol{H}$, The neuron responded to both noxious heat and cold stimuli applied to its cutaneous receptive field in a graded manner. $I$, Line graph showing the response of this cell to thermal stimuli.

locity was $5.0 \pm 0.3 \mathrm{~m} / \mathrm{s}$ (range of $2.4-8.8 \mathrm{~m} / \mathrm{s}$ ) (Fig. $8 A$ ). The mean conduction velocity for three lumbar STT axons was $8.6 \pm$ $0.7 \mathrm{~m} / \mathrm{s}$. The conduction velocities of different thermally responsive groups are shown in Figure 8 B. Although COOL-type cells appeared to have the fastest and nociceptive-specific cells and the slowest average conduction velocities, the differences between the groups were not significant $(p>0.05)$.

\section{Recording sites and axon} terminal localization

Thirty MZ neurons were recorded in the cervical enlargement and three in the lumbar enlargement. The locations of lesions marking 26 recovered recording sites in the cervical enlargement plus three in the lumbar enlargement are shown in Figure 9C. Four lesions in the cervical enlargement were not recovered, but each was recorded at a depth of $<100 \mu \mathrm{m}$ from the surface of the cord, indicating that these were also likely to be located in the MZ. No difference regarding the location of the recording points among the three functionally identified types of STT neurons could be determined (Fig. 9D).

All 30 neurons in the cervical enlargement and three neurons in the lumbar enlargement were antidromically activated from low-threshold points in the contralateral VPL of the thalamus (Fig. 9A). Each of these low-threshold points was surrounded medially, laterally, and rostrally by ineffective tracks in which $500 \mu \mathrm{A}$ current could not activate the neuron antidromically. In three cases, two separate low-threshold points from the same neuron were found in different nuclei within the thalamus. One low-threshold point from each of these three axons was located in VPL. Two neurons possessed an additional low-threshold point in the posterior nucleus of thalamus, and the other neuron was antidromically activated from a lowthreshold point in the dorsomedial nucleus. These results show that, in rats, some MZ STT neurons may have collateral branches that terminate in multiple thalamic nuclei as has been shown previously in monkey (Applebaum et al., 1979; Giesler et al., 1981). Five axons were activated from VPL at two different rostrocaudal levels. The low-threshold point at the caudal level always had a shorter latency, indicating the activation of an axon of passage. In these cases, as in all others, the most rostral point was surrounded and marked.

Most of the low-threshold points were located within the middle rostrocaudal extent of VPL $(-3.6$ and $-2.8 \mathrm{~mm}$ from bregma) (Fig. 9A). Each thermally identified subgroup of MZ STT neuron is plotted in Figure 9B. The low-threshold points of COOL-type axons were located an average of only $32.9 \pm 16.6 \mu \mathrm{m}$ from the border of VPM, significantly dorsal and medial relative to the polymodal and nociceptive-specific types of MZ cells (345.9 \pm 90.8 and $213.1 \pm 54.6 \mu \mathrm{m}$, respectively; $p<0.01)$. The three neurons recorded in the lumbar cord had projections to the hindlimb representation area in lateral VPL. The mean \pm SE current for antidromic activation from all 33 low-threshold points in the contralateral VPL of the thalamus was $23.4 \pm 1.3 \mu \mathrm{A}$. 


\section{Discussion}

The results from this study demonstrate that spinal cord marginal zone neurons transmit noxious mechanical and a wide range of thermal information directly to distinct regions of VPL in rats. All but a single examined MZ STT neuron that projected to VPL responded to thermal stimuli. Three groups of thermally responsive STT neurons in the MZ were identified, in agreement with previous studies in the cat and monkey (Dostrovsky and Craig, 1996; Craig et al., 2001). COOL cells responded in a graded manner to innocuous cool stimuli and maximally to noxious cold, but, unlike reports in the cat and monkey, COOL cells in the rat also responded consistently to noxious heat and noxious mechanical stimulation. Nociceptive-specific cells were activated by noxious heat and mechanical stimuli, and polymodal nociceptive cells responded to noxious heat, cold, and mechanical stimuli. Our results are consistent with the view that MZ STT neurons that project to VPL play an important role in sensory-discriminative aspects of thermal and mechanical pain sensation, including the quality, location, and intensity of the stimulation (Willis et al., 2002).

The activity of COOL cells increased linearly to decreasing innocuous cool stimulation from 30 to $15^{\circ} \mathrm{C}$, but, as temperatures decreased below $15-1^{\circ} \mathrm{C}$, these cells maintained a constant peak-firing rate. This result is consistent with previous studies that describe a saturated response beginning at $12.5^{\circ} \mathrm{C}$ in the monkey and $15^{\circ} \mathrm{C}$ in the cat, although cold stimuli below $9^{\circ} \mathrm{C}$ were not tested in these species (Dostrovsky and Craig, 1996; Craig et al., 2001). COOL cells in the rat spinal MZ had little activity when exposed to warm temperatures $\left(35-45^{\circ} \mathrm{C}\right)$, but high noxious temperatures $\left(50-55^{\circ} \mathrm{C}\right)$ elicited an intermittent response in each COOL cell. A corresponding stimulus-response pattern was documented in a class of primary afferent $A \delta$ fibers that responded in a graded manner to cooling but also "paradoxically" to intense heat (Dodt and Zotterman, 1952; LaMotte and Thalhammer, 1982).

Christensen and Perl (1970) recorded from cells responsive to innocuous cooling in the marginal zone of decapitated cats and found that approximately half responded to noxious mechanical and/or heat stimuli. In later studies, mechanical and heat sensitivity were tested in COOL cells identified as projecting to the thalamus of cat and monkey, but these rarely responded to mechanical stimulation and responded only weakly or not at all to noxious (paradoxical) heat (Dostrovsky and Craig, 1996; Craig et al., 2001). The temperatures tested were often just above noxious, and therefore a greater percentage could possibly have been activated with higher heat. Nevertheless, these results led to the conclusion that COOL cells projecting to the thalamus were part of a "labeled-line" that coded innocuous temperature (Craig et al., 2001). In the rat, however, many of the COOL cells recorded in
B
Polymodal

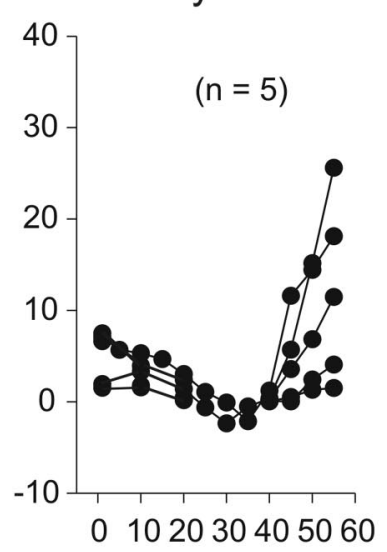

E

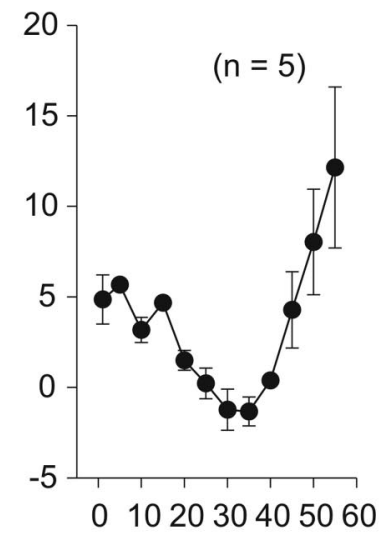

Stimulus Temperature $\left({ }^{\circ} \mathrm{C}\right)$

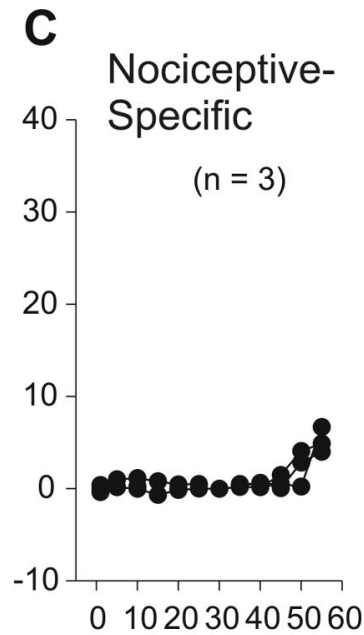

$\mathbf{F}$

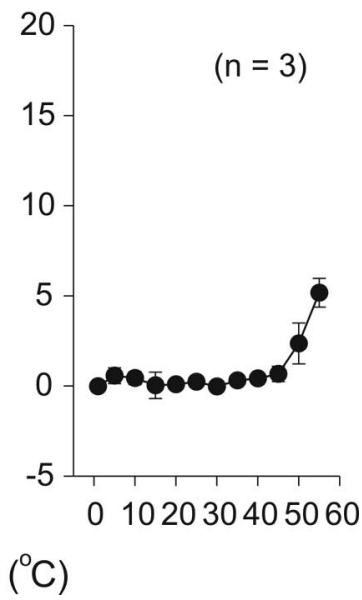

Figure 5. Stimulus-response plots for thermally identified subgroups of marginal zone neurons. $\boldsymbol{A}$, Individual responses of COL-type neurons to noxious heat, $\mathrm{CoOl}$, and noxious cold stimuli. $\boldsymbol{B}$, Polymodal nociceptive neurons responded in a graded manner to noxious heat and cold stimuli. $\boldsymbol{C}$, Nociceptive-specific neurons responded only to noxious heat. Mean \pm SE stimulusresponse curves for $\operatorname{COOL}(\boldsymbol{D})$, polymodal $(\boldsymbol{E})$, and nociceptive-specific-type $(\boldsymbol{F})$ cells.
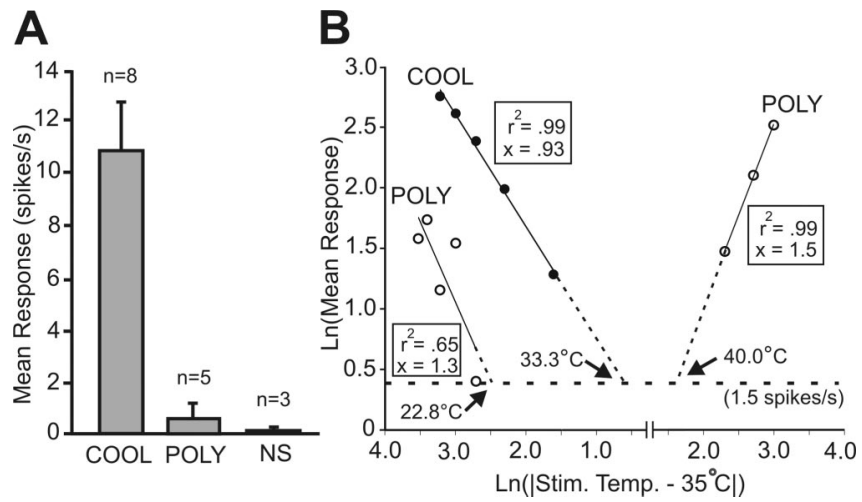

Figure 6. Characteristics of thermally defined subgroups of marginal zone neurons. $A$, At room temperature $\left(23^{\circ} \mathrm{C}\right), \mathrm{COOL}$-type neurons had a greater level of spontaneous activity $(10.8 \pm 1.8 \mathrm{~Hz})$ than the polymodal neurons (POLY) $(0.6 \pm 0.4 \mathrm{~Hz})$ or the nociceptive-specific neurons (NS) $(0.1 \pm 0.1 \mathrm{~Hz} ; p<0.01)$. B, Double-logarithmic plot describing the stimulusresponse functions of thermally tested subgroups within their temperature coding range. The abscissa represents the change in stimulus temperature from the holding temperature, and the ordinate represents the neural discharge frequency. The threshold for a response $(\geq 1.5$ spikes/s) is illustrated with a horizontal dotted line, and the threshold temperatures are indicated for each subgroup (arrows). The slope, $x$, of the regression line is equal to the exponent in Stevens' power law. A regression analysis was not completed for $\mathrm{COOL}$ and NS cells in the heating range because these subgroups responded to only two test temperatures. 


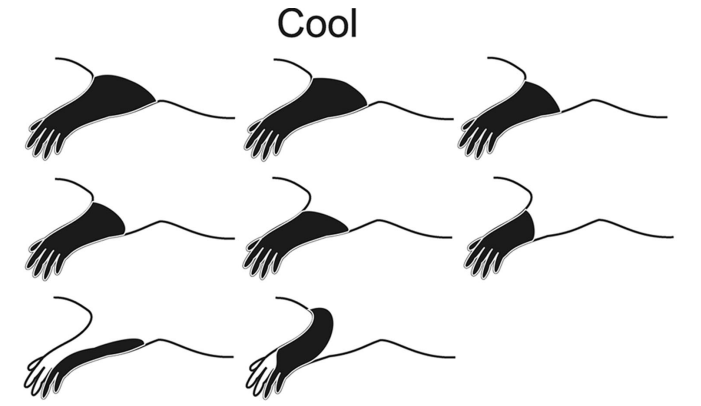

Nociceptive-specific

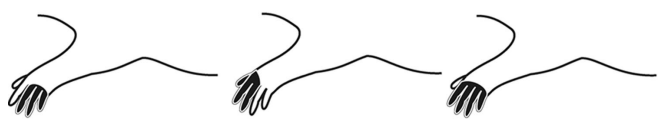

Not thermally tested

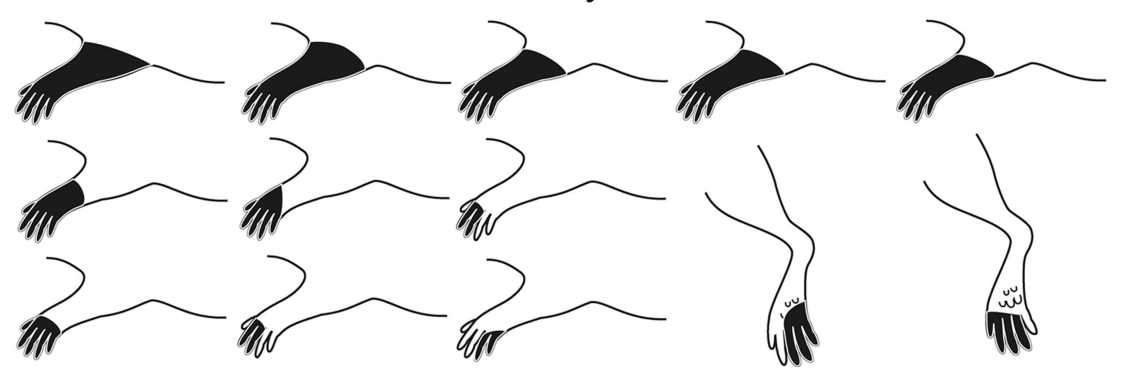

Figure 7. Cutaneous receptive fields of each examined MZ neuron with a projection to VPL. Receptive fields of COOL cells always included parts of the entire limb, including digits, paw, and limb. Polymodal and nociceptive-specific cells rarely had receptive fields as large. Only noxious mechanical stimulation applied to the receptive fields were adequate to activate MZ STT neurons projecting to VPL.
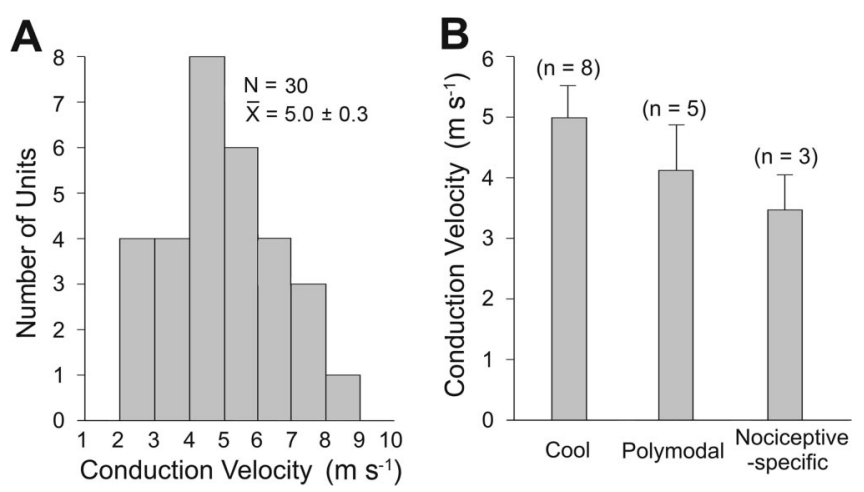

Figure 8. Conduction velocities of examined axons. $\boldsymbol{A}$, Conduction velocities of marginal zone STT neurons were measured from the recording site in the cervical enlargement to the low-threshold point in the contralateral VPL of the thalamus. $\boldsymbol{B}$, Comparison of conduction velocities of the three different groups of thermally responsive marginal zone neurons.

the superficial medullary dorsal horn responded to noxious heat and/or were responsive to innocuous or noxious mechanical stimulation (Hutchison et al., 1997). The present findings, that all spinal MZ COOL cells projecting to VPL in the rat responded to a squeeze with greater activity than to a pinch and to noxious heat stimuli, raises the question of whether COOL cells can code for any one modality with specificity.

All but a single (94\%) of the thermally examined MZ neurons that projected to VPL responded to noxious thermal stimuli. Half were classified as COOL, suggesting that this type is relatively
Polymodal
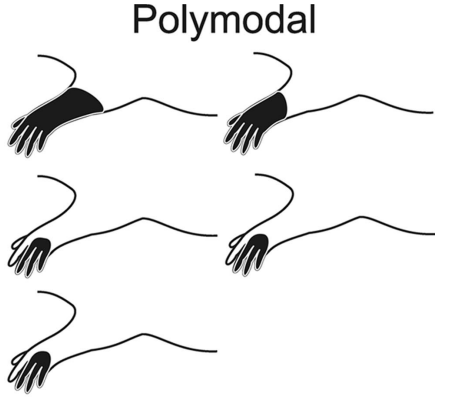

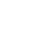

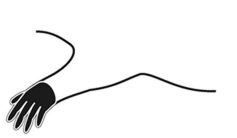

common in the rat. In a previous study, our laboratory reported that the MZ projection to the hypothalamus contained cells, $85 \%$ of which were responsive to noxious heat and only $23 \%$ responsive to cooling and/or noxious cold (Dado et al., 1994b). Only 60\% of MZ neurons that terminated in the rat posterior thalamus (Po) responded to noxious thermal stimuli, and none responded to innocuous temperatures (Zhang and Giesler, 2005). No rat $\mathrm{MZ}$ neuron with a projection to or through the parabrachial nuclei (PB) was responsive to innocuous cooling, and only one-third were responsive to noxious cold, although nearly all PB-projecting cells were responsive to noxious heat (Bester et al., 2000). It is clear that thermally sensitive MZ cells terminate in several regions of the diencephalon and brainstem, but the present findings point to VPL as the principal target for thermal discriminative processing, particularly for cool and cold temperatures.

The combined response properties of the three main types of MZ STT neurons appear to be able to account for much of the range of physiologically relevant environmental temperatures except, notably, for innocuous warm. Only $10 \mathrm{MZ}$ STT neurons in cats responded to innocuous warm temperatures from a sample of 474 (Andrew and Craig, 2001); therefore, a much larger sample of STT neurons in rats would likely be required to determine whether any neurons responsive to temperatures between 30 and $45^{\circ} \mathrm{C}$ exist. Although no cell in this study clearly responded to innocuous warming of its receptive field, some polymodal cells responded weakly to heat below the noxious range. The polymodal cells characterized in this study closely resemble the heatpinch-cold (HPC) cells documented in lamina I of the cat (Craig et al., 2001). In the cat, most of the HPC cells had a threshold for response to cooling above $20^{\circ} \mathrm{C}$ and a threshold to heating above $45^{\circ} \mathrm{C}$. Polymodal cells in the rat likewise responded weakly to innocuous cool temperatures above $20^{\circ} \mathrm{C}$ but also appeared to begin responding to heating at temperatures below $45^{\circ} \mathrm{C}$.

In psychophysical experiments, the perceived magnitude of a stimulus can be described by a power function of the stimulus magnitude (Stevens, 1970). Measurements on the perception of pain from contact noxious heat are described by power functions with exponents of $\sim 2.1$ (Price, 1988). The polymodal cells in this study responded to heat with a moderately accelerating stimulusresponse function described by an exponent of 1.5. In response to cooling and cold, polymodal cells had an exponent of 1.3 and a threshold for response at $22.8^{\circ} \mathrm{C}$. COOL cells responded with an exponent of 0.93 to innocuous temperatures, demonstrating near-linear coding in close agreement with psychophysical measures of cool to cold temperatures (Chery-Croze, 1983). The activity of thermally responsive subgroups of $\mathrm{MZ}$ neurons that project to VPL appear capable of contributing to the neural processing of cool, cold, and noxious heat intensity perception.

On the basis of their responses to mechanical stimuli, all MZ neurons projecting to VPL found in this study were classified as 
A
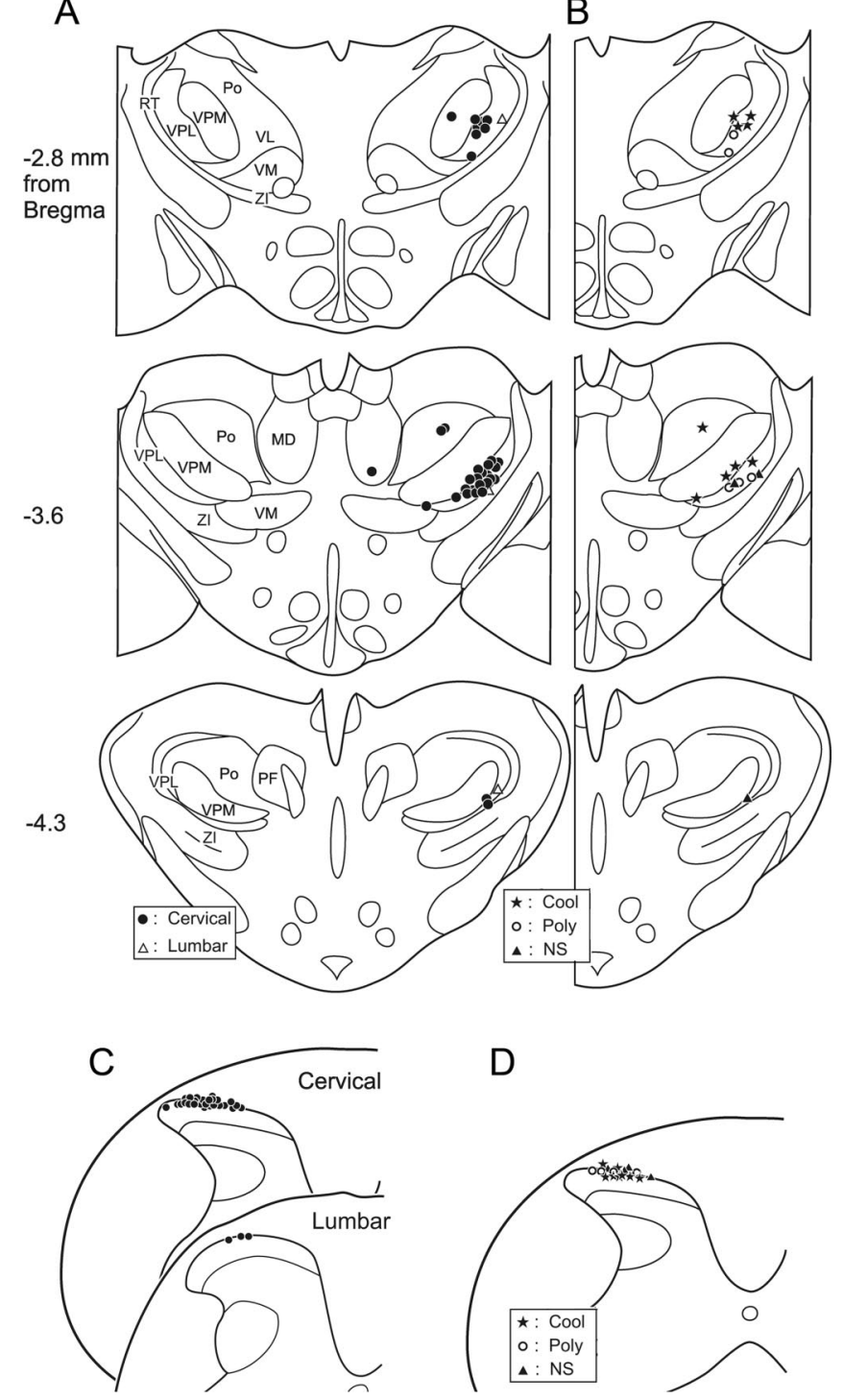

Figure 9. Summary of the locations of lesions in the thalamus and spinal cord marking 36 low-threshold points and 33 recording points. $A$, Locations of lesions marking 33 surrounded low-threshold points were in VPL, and three surrounded low-threshold points were located in other thalamic nuclei. The distance from bregma of each plane is indicated to the left of each section. MD, Mediodorsal thalamic nucleus; RT, reticular thalamic nucleus; VM, ventromedial thalamic nucleus; Zl, zona incerta; $\mathrm{PF}$, parafascicular thalamic nucleus; $\mathrm{VL}$, ventrolateral thalamic nucleus. $\boldsymbol{B}$, Locations of lesions marking low-threshold points of the three functionally identified subgroups of thermally responsive MZneurons. $C$, Recording sites of 26 neurons in the cervical enlargement and three neurons in the lumbar enlargement. $\boldsymbol{D}$, Illustration of the recording sites from 16 units divided into thermally responsive subgroups. Cool, COOL-type neurons; Poly, polymodal neurons; NS, nociceptive-specific neurons.

HT. No other ascending projection from the MZ in rat has been described in which all recorded neurons were activated only by noxious mechanical stimuli. In previous studies, $80 \%$ of rat MZ cells projecting to the posterior thalamus were classified as HT (Zhang and Giesler, 2005), 75\% of rat MZ cells projecting to the parabrachial nuclei were documented as HT (Bester et al., 2000), and MZ neurons projecting to the hypothalamus in rat were $\sim 50 \%$ HT (Burstein et al., 1991; Dado et al., 1994; Zhang et al., 2002). Therefore, VPL appears to be the principle target for MZ projection neurons with specific input from high-threshold mechanical nociceptors in rat. MZ STT neurons in the cat are almost exclusively HT (Craig and Kniffki, 1985), which contrasts with the MZ STT cells antidromically activated from VPL in monkeys in which WDR neurons account for approximately half of the population (Ferrington et al., 1987; Zhang et al., 2000).

Thermally identified subgroups of MZ STT neurons terminated within distinct areas of the rat VPL. Polymodal nociceptive and nociceptive-specific neurons projected to the ventral and lateral region of VPL, but COOL neurons terminated in the medial and dorsal region of VPL. In cats, functional classes of MZ spinothalamic neurons have been shown to possess discernible projections within the thalamus (Craig and Kniffki, 1985; Craig and Dostrovsky, 2001). However, in cats, the STT primarily projects to the ventral and medial borders of VP (Craig and Burton, 1985), a pattern that is different from monkeys and rats. In these species, the STT primarily terminates within VPL (Mehler, 1969; Gauriau and Bernard, 2004). Additionally, in the monkey, marginal zone nociceptive and thermoreceptive neurons have been reported to project to another region named "VMpo" located medial and posterior to VPL (Craig et al., 1994; Dostrovsky and Craig, 1996). Cells responsive to innocuous cooling have been recorded in monkey VPL, ventral posterior inferior nucleus, $\mathrm{Po}$, and the region of VMpo as well as in analogous areas of the human thalamus, although no localization of thermally responsive subareas within these nuclei has been established (Lenz et al., 1993; Apkarian and Shi, 1994; Craig et al., 1994; Lenz and Dougherty, 1998; Davis et al., 1999). Interestingly, cooling-responsive cells have been localized within the medial and dorsal area of VPM (Bushnell et al., 1993). The present results support the hypothesis that subareas of VPL have selective functions in sensory processing in rat. The ventral or ventrolateral area likely involves nociceptive processing, whereas innocuous cooling may be processed in the medial and dorsal region of VPL. Additional experiments localizing thermally responsive cells in VPL could more fully resolve the issue of subnuclear functional specialization.

The spinothalamic projection is a heterogeneous system. Previous studies along with the present work indicate that MZ neurons project to several different nuclei of the diencephalon as well as to other areas within the brainstem. Marginal zone neurons can transmit information about location, quality, and intensity to the somatosensory processing system in the thalamus and to parts of the limbic and autonomic systems. The results from this study show that MZ STT neurons that project directly to rat VPL consist of three main functional groups distinguishable by their responses to a range of temperatures. Each type likely receives specialized primary afferent input and sends a specific set of thermal and noxious mechanical information to different regions of VPL. These results support the case for compartmentalized regions of VPL as sites for specific thermal and mechanical processing.

\section{References}

Andrew D, Craig AD (2001) Spinothalamic lamina I neurons selectively responsive to cutaneous warming in cats. J Physiol (Lond) 537:489-495.

Apkarian AV, Shi T (1994) Squirrel monkey lateral thalamus. I. Somatic nociresponsive neurons and their relation to spinothalamic terminal. J Neurosci 14:6779-6795.

Applebaum AE, Leonard RB, Kenshalo Jr DR, Martin RF, Willis WD (1979) Nuclei in which functionally identified spinothalamic tract neurons terminate. J Comp Neurol 188:575-585.

Bester H, Chapman V, Besson JM, Bernard JF (2000) Physiological properties of the lamina I spinoparabrachial neurons in the rat. J Neurophysiol 83:2239-2259.

Blomqvist A, Zhang ET, Craig AD (2000) Cytoarchitectonic and immunohistochemical characterization of a specific pain and temperature relay, the posterior portion of the ventral medial nucleus, in the human thalamus. Brain 123:601-619. 
Burstein R, Dado RJ, Cliffer KD, Giesler Jr GJ (1991) Physiological characterization of spinohypothalamic tract neurons in the lumbar enlargement of rats. J Neurophysiol 66:261-284.

Bushnell MC, Duncan GH, Tremblay N (1993) Thalamic VPM nucleus in the behaving monkey. I. Multimodal and discriminative properties of thermosensitive neurons. J Neurophysiol 69:739-752.

Chery-Croze S (1983) Relationship between noxious cold stimuli and the magnitude of pain sensation in man. Pain 15:265-269.

Christensen BN, Perl ER (1970) Spinal neurons specifically excited by noxious or thermal stimuli: marginal zone of the dorsal horn. J Neurophysiol 33:293-307.

Craig AD (2004) Distribution of trigeminothalamic and spinothalamic lamina I terminations in the Macaque monkey. J Comp Neurol 477:119-148.

Craig AD, Burton H (1985) The distribution and topographical organization in the thalamus of anterogradely-transported horseradish peroxidase after spinal injection in cat and raccoon. Exp Brain Res 58:227-254.

Craig AD, Dostrovsky JO (2001) Differential projections of thermoreceptive and nociceptive lamina I trigeminothalamic and spinothalamic neurons in the cat. J Neurophysiol 86:856-870.

Craig AD, Kniffki KD (1985) Spinothalamic lumbosacral lamina I cells responsive to skin and muscle stimulation in the cat. J Physiol (Lond) 365:197-221.

Craig AD, Bushnell MC, Zhang ET, Blomqvist A (1994) A thalamic nucleus specific for pain and temperature sensation. Nature 372:770-772.

Craig AD, Krout K, Andrew D (2001) Quantitative response characteristics of thermoreceptive and nociceptive lamina I spinothalamic neurons in the cat. J Neurophysiol 86:1459-1480.

Dado RJ, Katter JT, Giesler Jr GJ (1994a) Spinothalamic and spinohypothalamic tract neurons in the cervical enlargement of rats. I. Locations of antidromically identified axons in the thalamus and hypothalamus. J Neurophysiol 71:959-980.

Dado RJ, Katter JT, Giesler Jr GJ (1994b) Spinothalamic and spinohypothalamic tract neurons in the cervical enlargement of rats. II. Responses to innocuous and noxious mechanical and thermal stimuli. J Neurophysiol 71:981-1002.

Davis KD, Lozano RM, Manduch M, Tasker RR, Kiss ZH, Dostrovsky DO (1999) Thalamic relay site for cold perception in humans. J Neurophysiol 81:1970-1973.

Dodt E, Zotterman Y (1952) The discharge of specific cold fibres at high temperatures. (The paradoxical cold.) Acta Physiol Scand 26:358-365.

Dostrovsky JO, Craig AD (1996) Cooling-specific spinothalamic neurons in the monkey. J Neurophysiol 76:3656-3665.

Ferrington DG, Sorkin LS, Willis Jr WD (1987) Responses of spinothalamic tract cells in the superficial dorsal horn of the primate lumbar spinal cord. J Physiol (Lond) 388:681-703.

Gauriau C, Bernard JF (2004) A comparative reappraisal of projections from the superficial laminae of the dorsal horn in the rat: the forebrain. J Comp Neurol 468:24-56.

Giesler Jr GJ, Yezierski RP, Gerhardt KD, Willis WD (1981) Spinothalamic tract neurons that project to medial and/or lateral thalamic nuclei: evidence for a physiologically novel population of spinal cord neurons. J Neurophysiol 46:1285-1308.

Graziano A, Jones EG (2004) Widespread thalamic termination of fibers arising in the superficial medullary dorsal horn of monkeys and their relation to calbindin immunoreactivity. J Neurosci 24:248-256.

Han ZS, Zhang ET, Craig AD (1998) Nociceptive and thermoreceptive lamina I neurons are anatomically distinct. Nat Neurosci 1:218-225.
Hutchison WD, Tsoukatos J, Dostrovsky JO (1997) Quantitative analysis of orofacial thermoreceptive neurons in the superficial medullary dorsal horn of the rat. J Neurophysiol 77:3252-3266.

LaMotte RH, Thalhammer JG (1982) Response properties of highthreshold cutaneous cold receptors in the primate. Brain Res 244:279-287.

Lenz FA, Dougherty PM (1998) Neurons in the human thalamic somatosensory nucleus (ventralis caudalis) respond to innocuous cool and mechanical stimuli. J Neurophysiol 79:2227-2230.

Lenz FA, Seike M, Richardson RT, Lin YC, Baker FH, Khoja I, Jaeger CJ, Gracely RH (1993) Thermal and pain sensations evoked by microstimulation in the area of human ventrocaudal nucleus. J Neurophysiol 70:200-212.

Light AR, Trevino DL, Perl ER (1979) Morphological features of functionally defined neurons in the marginal zone and substantia gelatinosa of the spinal dorsal horn. J Comp Neurol 186:151-172.

Lipski J (1981) Antidromic activation of neurons as an analytic tool in the study of the central nervous system. J Neurosci Methods 4:1-32.

Mehler WR (1969) Some neurological species differences: a posteriori. Ann NY Acad Sci 167:424-468.

Paxinos G, Watson C (1986) The rat brain in stereotaxic coordinates. New York: Academic.

Price DD (1988) Psychological and neural mechanisms of pain. New York: Raven.

Price DD, Hayes RL, Ruda MA, Dubner R (1978) Spatial and temporal transformations of input to spinothalamic tract neurons and their relation to somatic sensations. J Neurophysiol 41:933-947.

Simone DA, Zhang X, Li J, Zhang JM, Honda CN, LaMotte RH, Giesler Jr GJ (2004) Comparison of responses of primate spinothalamic tract neurons to pruritic and algogenic stimuli. J Neurophysiol 91:213-222.

Stevens SS (1970) Neural events and the psychophysical law. Science 170:1043-1050.

Todd AJ, Spike RC, Young S, Puskár Z (2005) Fos induction in lamina I projection neurons in response to noxious thermal stimuli. Neuroscience 131:209-217.

Wilcox GL, Giesler Jr GJ (1984) An instrument using multiple layer peltier devices to change skin temperature rapidly. Brain Res Bull 12:143-146.

Willis Jr WD, Trevino DL, Coulter JD, Maunz RA (1974) Responses of primate spinothalamic tract neurons to natural stimulation of hindlimb. J Neurophysiol 37:358-372.

Willis Jr WD, Zhang X, Honda CN, Giesler Jr GJ (2001) Projections from the marginal zone and deep dorsal horn to the ventrobasal nuclei of the primate thalamus. Pain 92:267-276.

Willis Jr WD, Zhang X, Honda CN, Giesler Jr GJ (2002) A critical review of the role of the proposed VMpo nucleus in pain. J Pain 3:79-94.

Zhang X, Giesler Jr GJ (2005) Response characteristics of spinothalamic tract neurons that project to the posterior thalamus in rats. J Neurophysiol 93:2552-2564.

Zhang X, Kostarczyk E, Giesler Jr GJ (1995) Spinohypothalamic tract neurons in the cervical enlargement of rats: descending axons in the ipsilateral brain. J Neurosci 15:8393-8407.

Zhang X, Wenk HN, Honda CN, Giesler Jr GJ (2000) Locations of spinothalamic tract axons in cervical and thoracic spinal cord white matter in monkeys. J Neurophysiol 83:2869-2880.

Zhang X, Gokin AP, Giesler Jr GJ (2002) Responses of spinohypothalamic tract neurons in the thoracic spinal cord of rats to somatic stimuli and graded distention of the bile duct. Somatosens Mot Res 19:5-17. 